\title{
Care in times of COVID-19: the impact of the pandemic on informal caregiving in Austria
}

\author{
Ricardo Rodrigues $^{1}(10) \cdot$ Cassandra Simmons $^{1} \cdot$ Andrea E. Schmidt $^{2}\left([) \cdot\right.$ Nadia Steiber $^{3,4}(\mathbb{C}$
}

Accepted: 22 February 2021 / Published online: 12 March 2021

(c) The Author(s), under exclusive licence to Springer Nature B.V. 2021

\begin{abstract}
Much attention has been paid to the effects of the COVID-19 pandemic on long-term care but the impact on informal caregivers has remained speculative. In Austria, like in other European countries, informal care is carried out overwhelmingly by (non-cohabiting) relatives. Limited care services available during the pandemic, social-distancing, increased unemployment and competing care needs within households (e.g. due to school closures) may have changed the prevalence and intensity of informal caregiving. Moreover, these changes may have increased the psychological strain experienced by caregivers. Focusing on Austria, this study aims to empirically analyse the following research questions: how have the prevalence and intensity of informal care changed due to the pandemic? How has the psychological well-being of informal caregivers been affected? We use a pre- and post-onset of the pandemic research design based on a representative survey carried out in Austria in June $2020(N=2000)$ in combination with comparable 2015 data from the European Social Survey. Findings suggest that neither prevalence nor intensity of informal care changed significantly due to the pandemic. However, the psychological well-being gap between carers and non-carers increased with the start of the pandemic, especially among men. Findings are discussed in relation to the policy measures implemented and possible policy implications for the future.
\end{abstract}

Keywords COVID-19 $\cdot$ Informal care $\cdot$ Psychological wellbeing $\cdot$ Quantitative methods

\section{Introduction}

At the onset of the pandemic, many countries failed to acknowledge the importance of the long-term care (LTC) sector to protect older people in need of care, who were particularly at risk of infection and mortality due to SARSCoV-2 (Comas-Herrera et al. 2020; Lorenz-Dant 2020). While the limelight has been firmly set on the LTC sector, in particular care homes, informal carers have received comparatively less attention (WHO 2020). Informal carers providing support to family members shoulder a large bulk of

Responsible editor: Marja J.Aartsen.

Ricardo Rodrigues

rodrigues@euro.centre.org

1 European Centre for Social Welfare Policy and Research, Vienna, Austria

2 Austrian National Public Health Institute, Vienna, Austria

3 Department of Sociology, University of Vienna, Vienna, Austria

4 Institute for Advanced Studies, Vienna, Austria the burden of care, particularly in familialistic welfare states (Barczyk and Kredler 2019). In Austria, around one million people provide unpaid care to family members, friends or neighbours, and it is estimated that more than 40 per cent of people in need of care are cared for only by family members (Nagl-Cupal et al. 2018).

Informal carers may have been particularly vulnerable to the consequences of the pandemic, even if not necessarily to the effects of the virus itself (Lorenz-Dant 2020). To date, however, there is a dearth of reliable data on how the onset of the pandemic has affected informal carers in comparison with non-carers. Most available studies are limited to convenience sample surveys targeting only informal carers. Taking advantage of unique data from a representative survey of Austria's working age population collected three months after the onset of the COVID-19 pandemic, this study aims to bridge this gap in knowledge. Specifically, it has two main research questions: Have the prevalence or intensity of informal care changed due to the pandemic? And what implications did the first wave of the pandemic have in regard to the psychological well-being of informal caregivers? After an overview of the measures implemented in Austria and 
the presentation of hypotheses, we describe the data and methods used. Subsequently, we present our main findings and conclude with a discussion of vulnerabilities of informal caregivers highlighted by the pandemic and possible policy implications.

\section{The Austrian experience with COVID-19}

The management of the COVID-19 pandemic in Austria involved the early implementation of relatively stringent measures. Based on the Government Response Stringency Index (Hale et al. 2020), Austria ranked 9th out of $26 \mathrm{EU}$ countries for which data were available at the outset of the pandemic (data from 8 April 2020) but relaxed measures more quickly than others, ranking 14 th by mid-June. The country's first lockdown extended to shops, restaurants, but also schools and kindergartens, and lasted from mid-March to the end of April approximately. Care homes were closed for visitors during the lockdown and re-opened gradually from mid-April onwards, together with announced plans for a comprehensive screening of all staff and residents (BMSGPK 2020). For community care services however, no federal guidelines were issued. Anecdotal reports show that community care was reduced to a minimum, e.g. for people in need of care who lived alone (Schmidt et al. 2020). As other European countries, Austria also sealed its borders in the early stages of the crisis to all but essential travel. Privately paid live-in domestic assistants of primarily migrant origin were thus either prevented from returning to their countries or locked out of the country. Despite the reliance on care provided by family members, specific support measures targeted at informal carers relied heavily on support from third sector organisations. Regional governments received federal funding to help fund alternative sources of LTC provision where informal carers would drop out (Schmidt et al. 2020).

At the time of the survey, Austria had moved towards a less stringent level of restrictions, as schools had reopened and care homes were open for visitors again (see Schmidt et al. 2020). However, the economic effects of the lockdown were already clearly visible and in the second quarter of 2020, the unemployment rate had risen to $5.7 \%$ (from $4.4 \%$ in a similar period in 2019) and the number of inactive working age people had more than doubled (Statistik Austria 2020).

\section{Impact of the pandemic on informal care provision}

A growing body of studies have linked the pandemic to changes in the prevalence and intensity of informal care (Lorenz-Dant 2020; Gräler et al. 2020; Maccora et al. 2020; Carers UK 2020; Eurocarers 2020; Rothgang and Wolf-Ostermann 2020). A number of countries have reported a reduction in community services, either in order to protect care recipients from COVID-19, or due to general regulations to close down certain services for the period of the pandemic (c.f. Carers UK 2020). In countries with a high reliance on privately paid live-in domestic assistants-who are mainly migrant carers, such as in Italy, Germany or Austria - the closure of borders added to the shortage of care alternatives (Schmidt et al. 2020; Lorenz-Dant 2020). Relatives may have had to step in to fill in the care gaps thus created, increasing care prevalence or intensity. A qualitative study on informal carers in the UK confirmed that fear of contagion by professional carers led informal caregivers to increase care hours as formal care was discontinued (Giebel et al. 2020). Concomitantly, studies from the UK, Australia, Norway and Germany report that informal caregivers faced a diminished availability of other family members to provide care (Maccora et al. 2020; Carers UK 2020; Eurocarers 2020; Rothgang and Wolf-Ostermann 2020; Volkshilfe 2020; Evandrou et al. 2020). This tightening of caring networks may have arisen from contagion fears and social distancing rules that often mandated older people to limit the number of persons with whom they have contact, including non-co-residing relatives. There is also evidence that more sporadic support from a larger network of family members in carrying out tasks such as accompanying older people to medical appointments was reduced during the crisis (Volkshilfe 2020; Maccora et al. 2020).

There are thus two possible counteracting forces at play: replacement of discontinued formal care with informal care (i.e. higher prevalence) and tighter caring networks due to fear of contagion or competing care needs (i.e. lower prevalence). Most existing studies have been unable to determine which effect has prevailed as they have gathered information on informal carers only, thus not allowing for changes in prevalence to be calculated. Whether the share of informal carers in the population has diminished or increased during the pandemic and to what degree informal carers have increased or decreased the time spent caring remain open empirical questions that we will assess. Based on the logic of diminished care services, we may expect the prevalence of informal care to have increased due to the pandemic (Hypothesis 1). Alternatively, prevalence may have remained stable, while care intensity increased (Hypothesis 2). Based on the logic of retracted care from carers with competing care needs or fear of contagion, we 
may expect the prevalence of informal care to have decreased due to the pandemic (Hypothesis 3).

\section{Impact of the pandemic on informal carers' psychological well-being}

It is well-documented that the COVID-19 pandemic has had dramatic consequences for the psychological well-being of the general population (Cénat et al. 2021). Informal caregivers are likely to face additional stressors related to the pandemic and are thus likely to be even more strongly impacted (Kent et al. 2020): emotional stress and isolation due to fear of contracting the virus and infecting relatives; economic stress associated with job loss for which carers are at heightened risk; health stress as access to routine healthcare for themselves and caredfor persons has become more difficult. Early evidence seems to confirm negative effects for caregivers (Gräler et al. 2020). In Germany, results from an online survey of informal caregivers showed that health condition worsened for more than half of carers, as did self-assessed quality of life (Rothgang and WolfOstermann 2020). Similar results were found in the UK (Carers UK 2020, Carers Trust 2020): caregivers reported social isolation, stress and deteriorating mental health. A longitudinal online survey in Austria shows that caregivers facing problems in organising care were significantly less satisfied with their lives than other caregivers (Kalleitner 2020). In view of this evidence, we hypothesize that psychological well-being deteriorated more strongly among carers in comparison with the general population (Hypothesis 4).

Reduced care services, particularly the possibility to take respite care, and reduced social contacts may have further deteriorated the psychological well-being of those providing intensive care. Due to a reduction in available therapies and rehabilitative services for people in need of intensive care, symptoms of cared-for people may have worsened, possibly increasing the complexity and burden of care among intensive caregivers (see Volkshilfe 2020). The deterioration in psychological well-being is thus likely to have been particularly pronounced among high-intensity carers (Hypothesis $5)$.

Caregiving in times of COVID-19 is likely to be particularly stressful for women, as infectious disease outbreaks tend to reinforce norms that condition women to caregiving roles (Connor et al. 2020). Women are more often the primary caregiver for older people residing outside the household, and more likely to shoulder other unpaid tasks such as childcare or housework. Lockdown measures such as confinement at home and home schooling may exacerbate an unequal division of responsibilities at home (Douglas et al. 2020; Craig and Churchill 2020), which is a key determinant of poor mental health for women (Marchand et al. 2016). We may therefore expect any increase in the negative impact of caregiving on psychological well-being due to the pandemic to be larger for female than for male caregivers (Hypothesis 6).

\section{Data and methods}

We take a two-pronged approach to test the above hypotheses. For the impact of the pandemic on the prevalence and intensity of informal caregiving (Hypotheses 1-3) we use data from a representative survey of working age residents in Austria (AKCOVID), in which respondents were asked questions in retrospect to February 2020 and in reference to the time of the survey, i.e. June 2020. This 'quasi-longitudinal' design allows for a pre-onset and post-onset comparison of informal caregiving. The retrospective data collected in the AKCOVID survey focus on relatively objective questions (e.g. employment, number of hours of caregiving), have a short recollection lag (up to four months) and refer to a landmark life event (the onset of a pandemic) for which recall bias is likely to be limited.

Collecting retrospective data on psychological wellbeing was deemed methodologically unfeasible. To assess the impact of the pandemic on psychological well-being we follow the example of other studies that compare data collected post-onset of the pandemic with comparable datasets collected before the onset to provide a pre-pandemic baseline (Ettman et al. 2020; McGinty et al. 2020). In this case we pooled the AKCOVID data with wave 7 of the European Social Survey (ESS) for Austria fielded in 2015.

\section{Data}

The AKCOVID is a representative survey carried out in Austria between 18 June and 2 July 2020. A mixed mode design was applied with $80 \%$ of respondents taking part in an online survey (CAWI) whereas $20 \%$ were interviewed by telephone (CATI). The sample involved 2000 respondents aged 20-64. To survey a representative sample of the Austrian population in these age brackets, quota sampling has been applied. To this end, the population was divided into strata defined by gender, age, education, household size, number and age of children, and NUT2-regions, and samples were taken from each of the subgroups defined by these characteristics. Additionally, post stratification weights have been constructed to reduce potential sampling errors and non-response bias. The population distributions for the adjustment variables gender, age group, education, household size, and region were obtained from the Austrian statistical office.

The ESS is an international survey on adults aged 15 and over that uses strict random sampling and face-to-face data collection. It is carried out bi-annually by IFES, which has also collected the AKCOVID data. As face-to-face 
interviewing is not possible during a pandemic, ESS data collection has come to a halt. To allow for comparisons of data collected at earlier time points with data collected during the pandemic, without resorting to retrospective questions on subjective well-being that would most likely result in bias, some concessions needed to be made in terms of methodical rigour. With this caveat in mind, we set out to compare analyses of the impact of caregiving on mental well-being from 2015 collected within the ESS with similar analyses based on AKCOVID data collected during the pandemic (see Table A in the Supplementary Material for original questions and response options). Previous studies have confirmed the validity of combining probabilistic with nonprobabilistic samples when applying multivariate regression (Ansolabehere and Rivers 2013; Pasek 2016) or compared quota sampling with the ESS and showed estimates to be of similar quality (cf. Revilla et al. 2015).

\section{Dependent variables: measures of care}

In this study, and both surveys, informal caregiving is defined as providing care or help to sick, disabled or frail family members, friends or neighbours (but excluding care related to a paid job). The prevalence of informal care for Hypotheses 1-3 (dichotomous variable indicating informal care of more than one hour per week) is assessed in relation to February 2020 (pre-onset) and the time of the AKCOVID survey (post-onset). Moreover, we construct a categorical variable defining three subgroups of carers based on AKCOVID data: continuous carers who provided informal care both in February and June 2020, those that began caring post-onset, and previous carers that stopped caring between February and June 2020. Finally, from AKCOVID, we construct a dichotomous variable measuring intensive care defined as providing care for more than 20 weekly hours (Colombo et al. 2011) and a continuous variable on the average weekly number of informal care hours provided, in both cases in reference to February and June 2020. For the ESS we construct similar variables for the prevalence and intensity of care for 2015, except for the continuous variable on the latter. ${ }^{1}$

As shown in Table 1, which provides basic descriptive statistics of the ESS and the AKCOVID sample, the prevalence of informal care decreased from about $19 \%$ in 2015 to about $14 \%$ in 2020 . This would be in line with expectations, given policy changes in Austria in recent years, which worked to the effect of increasing formal care support and thus potentially decreasing the need for informal care (BMASGK 2019).

\footnotetext{
${ }^{1}$ Intensity of care is measured continuously in the AKCOVID and in 10 -h intervals in the ESS.
}

Table 1 Descriptive statistics

\begin{tabular}{|c|c|c|c|}
\hline \multirow[t]{2}{*}{ Variable } & ESS wave 7 (2015) & $\begin{array}{l}\text { AKCOVID } \\
\text { (June 2020) }\end{array}$ & \multirow[t]{2}{*}{$p$-value } \\
\hline & $\%$ (mean) & $\%($ mean $)$ & \\
\hline CES-D & $(12.52)$ & $(17.82)$ & $<0.001$ \\
\hline Informal caregiving & 18.66 & 13.99 & $<0.001$ \\
\hline Intensive informal care ${ }^{\mathrm{a}}$ & 3.06 & 2.55 & 0.428 \\
\hline \multicolumn{4}{|l|}{ Gender } \\
\hline Women & 49.30 & 47.58 & \multirow[t]{2}{*}{0.115} \\
\hline Men & 50.70 & 52.42 & \\
\hline Age (mean) & $(41.58)$ & $(42.35)$ & \multirow{6}{*}{0.088} \\
\hline $20-29$ & 19.94 & 20.28 & \\
\hline $30-39$ & 25.89 & 22.27 & \\
\hline $40-49$ & 23.93 & 22.69 & \\
\hline $50-59$ & 22.60 & 25.92 & \\
\hline $60-64$ & 7.63 & 8.84 & \\
\hline \multicolumn{4}{|l|}{ Youngest child } \\
\hline $0-6$ & 12.56 & 16.97 & \multirow[t]{3}{*}{$<0.001$} \\
\hline $7-18$ & 17.49 & 24.36 & \\
\hline $18+/$ no children & 69.95 & 58.67 & \\
\hline \multicolumn{4}{|l|}{ Education } \\
\hline Primary & 17.46 & 13.55 & \multirow[t]{3}{*}{$<0.001$} \\
\hline Secondary & 45.61 & 56.76 & \\
\hline Tertiary & 36.93 & 29.69 & \\
\hline \multicolumn{4}{|l|}{ Birth country } \\
\hline Austria & 90.62 & 89.27 & \multirow[t]{3}{*}{0.272} \\
\hline Foreign-born & 9.38 & 10.73 & \\
\hline No. of observations & 1308 & 2000 & \\
\hline
\end{tabular}

Bold indicates significant values at $* \mathrm{p}<0.05 ; * * \mathrm{p}<0.01$; *** $\mathrm{p}<$ 0.001

Source AKCOVID and ESS wave 7. Both include only people aged 20-64 years old. Weighted results

${ }^{\mathrm{a}}$ More than $20 \mathrm{~h}$ of care per week

\section{Dependent variables: measures of psychological wellbeing}

The ESS and the AKCOVID include the same variant of the Center for Epidemiologic Studies Depression Scale (CES-D) that is based on the sum score of seven items of self-reported feelings associated with depression. Respondents were asked about the frequency at which they experienced each feeling in the previous week, using a four-point response scale (Table A in the Supplementary Material for original questions and response options). The seven items were summed to create an additive index, ranging from 0 to 60 (Cronbach's alpha of 0.83 ) with higher values indicating worse psychological outcomes (an approach used in other studies on the psychological well-being of caregivers, e.g. Verbakel et al. 2017; Taylor et al. 2008; Giovanetti et al. 2009). As shown in Table 1, the average level of depressive symptoms has 
substantially increased between 2015 and 2020, which is in line with the current literature (McGinty et al. 2020).

\section{Covariates}

To determine the impact of the pandemic, we use an independent variable for pre-onset/post-onset of the pandemic called 'post-onset'. For the test of Hypotheses 1-3 using AKCOVID data, this is a dummy variable that takes the value of 0 for February 2020 and 1 for June 2020. For the test of Hypotheses 4-6, 'post-onset' is a dummy variable that takes the value of 0 for 2015 (ESS) and 1 for June 2020 (AKCOVID). Further independent variables for both AKCOVID and ESS include age group, gender, education level (ISCED 2011), household size, foreign-born status and a categorical variable on the age of the youngest child. Categories of the latter include: between 0 and 6 years old, between 7 and 17 years old, or no co-residing underage children. AKCOVID includes two time-varying independent variables: employment status and self-reported ability to meet financial needs at the household level, each referring to February 2020 (retrospectively) and to the time of the survey. For the ESS both variables are time-invariant and refer only to the time of the survey (2015).

\section{Methods}

The analysis consists of two parts. To test Hypotheses 1-3, we calculate the prevalence and intensity of informal care pre- and post-onset of the pandemic on the AKCOVID sample. We use bivariate analysis employing F-statistics to discern differences between the time points. We also compare the socio-demographic profile of carers and non-carers between the two time points to analyse potential compositional changes due to the pandemic.

For the multivariate analysis on psychological wellbeing, the above depicted dichotomous variables on informal caregiving and intensive caregiving for 2015 and June 2020 are used as independent variables to help determine whether the effect of caregiving on psychological well-being changed with the pandemic. To test Hypotheses 4-6, we use a pooled sample that includes the AKCOVID and ESS samples aged 20-64. Using multivariate linear regression models (OLS) we estimate the effects of informal caring and of the pandemic ('post-onset') on psychological well-being and assess interaction effects between the caregiving status and 'postonset' (Hypothesis 4) and between intensive caregiving and 'post-onset' (Hypothesis 5). This approach is similar to a quasi-experimental difference-in-difference approach in order to compare the CES-D score between carers and noncarers and between intensive carers and less-intensive carers at two points in time. To test Hypothesis 6, the interaction term of caregiving and 'post-onset' is estimated separately
Table 2 Prevalence and intensity of informal caregiving before and during the pandemic

\begin{tabular}{lccc}
\hline Variable & $\begin{array}{l}\text { Feb 2020 } \\
\%(\text { mean) }\end{array}$ & $\begin{array}{l}\text { June 2020 } \\
\% \text { (mean) }\end{array}$ & $p$-value $^{\mathrm{a}}$ \\
\hline Dependent variables & & & \\
$\quad$ Caregiving & 12.84 & 13.99 & 0.345 \\
Intensive caregiving & \\
Hours of care (mean) $^{\mathrm{c}}$ & 2.54 & 2.55 & 0.982 \\
& $(15.27)$ & $(14.06)$ & 0.529 \\
\hline
\end{tabular}

Source Weighted results for AKCOVID. Sample: 2000 respondents aged 20-64

${ }^{\mathrm{a}}$ Difference between time periods. ${ }^{\mathrm{b}}$ More than $20 \mathrm{~h}$ of care per week. ${ }^{\mathrm{c}}$ Conditional on providing any hour of informal care

for women and men. The analyses were performed with Stata 15.0 statistical software.

\section{Results}

There is no statistically significant difference in the share of the population providing informal care pre- and post-onset of the pandemic (Table 2 indicating prevalence rates of 13\% and $14 \%$, respectively). Moreover, few changed their caregiving status between the two points in time: those who stopped caring between February and June 2020 represent 9.9\% of carers pre-onset, while new carers represent $14.7 \%$ of informal carers in June 2020. The prevalence of informal care therefore has not fundamentally changed post-onset of the pandemic (partial confirmation of Hypothesis 2).

The average number of hours of caregiving (conditional on caregiving) and the share of carers providing intensive care are also similar between the pre- and post-onset periods of the pandemic (Table 2). Although the conditional mean intensity decreased by over one hour post-onset, this decrease is not statistically significant. To gain further insights into changes in intensity of caregiving however, we compare the distribution of hours of continuous carers, those who started to care post-onset and previous carers who stopped when the pandemic hit (Fig. 1). The average number of hours of caregiving prior to and during the crisis by continuous carers remained at a similar level (15.7 versus $15.5 \mathrm{~h}$, not statistically significant at $95 \%$ level). The majority of continuous carers did also not change their care intensity (55\%), but $27 \%$ increased their hours, while $17 \%$ reduced their care hours. Continuous carers who increased their hours did so on average by about $6 \mathrm{~h}$, while those who reduced their hours did so by about $11 \mathrm{~h}$. The majority of those who stopped and those who started to care during the crisis provided $10 \mathrm{~h}$ of care per week or less, on average. Those who stopped caring tended to provide on average slightly more care prior to the pandemic $(10.8 \mathrm{~h})$, compared to those who started caring post-onset $(6.8 \mathrm{~h})$. Taken 
Continuous carers pre- and post-onset of pandemic $(\mathrm{N}=237)$

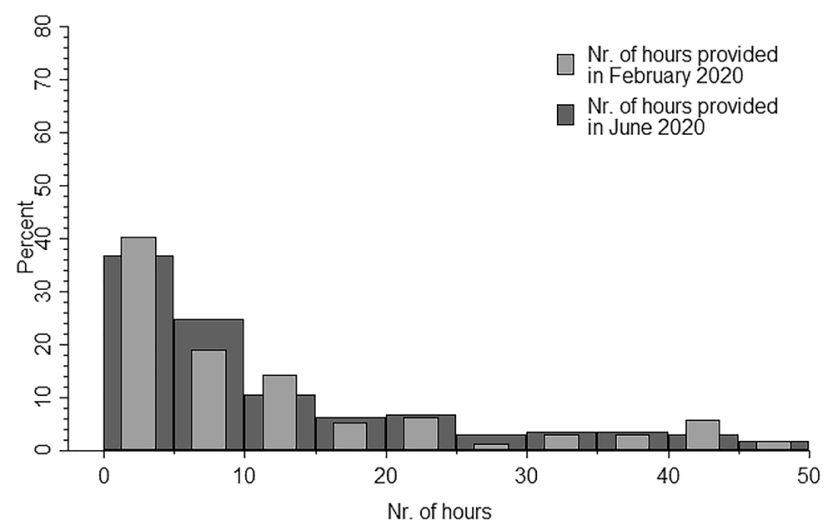

Stopped caring post-onset of pandemic $(\mathrm{N}=26)$

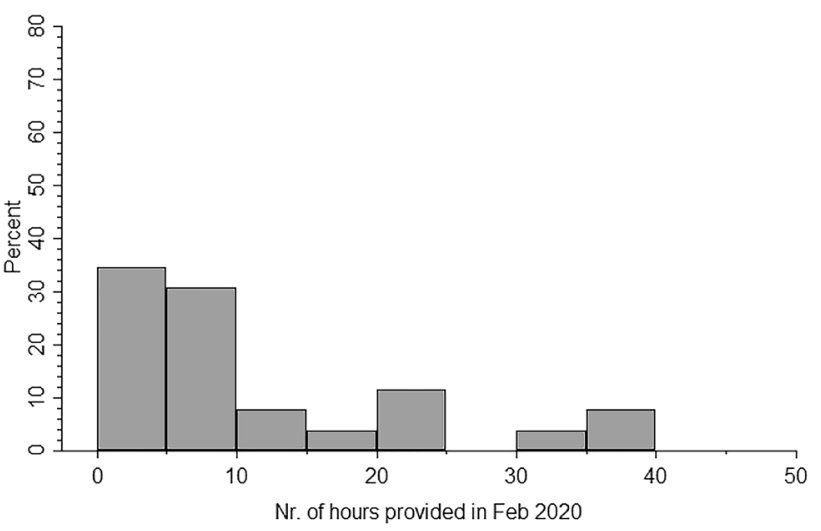

Started caring post-onset of pandemic $(\mathrm{N}=41)$

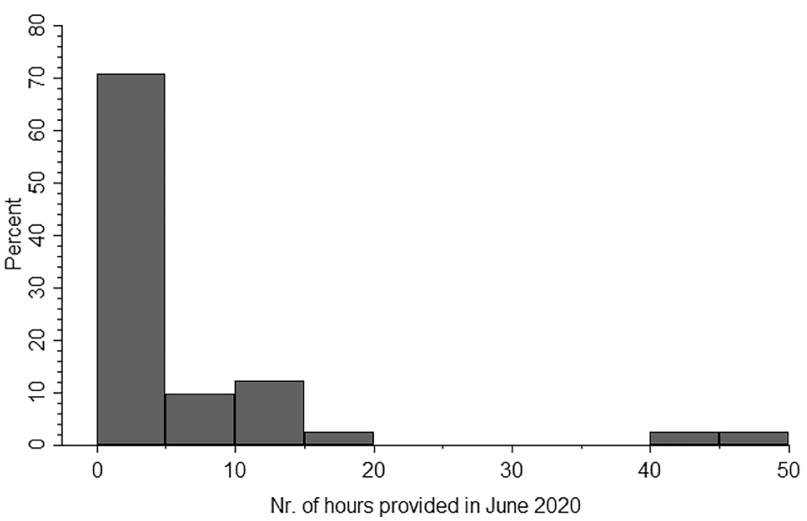

Fig. 1 Distribution of caregiving hours by care group. Source: Weighted results for AKCOVID

together, these results do not support the hypothesis of increasing care intensity (Hypothesis 2) nor of any changes in prevalence (Hypotheses 1 and 3).

While changes to prevalence and intensity of informal care are limited, this could mask a re-composition of carers between the two time points. Table 3 shows the results from F-tests that compare carers to non-carers pre- and post-onset of the pandemic. Prior to the onset of the pandemic, there was a broad resemblance between the profile of carers and non-carers, with the exception of age and gender. After the onset of the COVID-19 crisis in Austria, informal carers continued to be predominantly female and older, but they were less likely to have young children or to be born outside of Austria. Informal carers post-onset were also more likely to express difficulties in meeting financial needs and to be out of employment than non-carers-a difference that was not statistically significant before the pandemic.

Next, we turn our attention to the impact of the pandemic on the burden of caregiving (i.e. the gap in psychological well-being between carers and non-carers). Table 4 presents the weighted mean CES-D scores for non-carers and carers, disaggregated by care intensity and gender in 2015 and June 2020. While differences in CES-D scores between non-carers and carers were non-significant in 2015, this gap appears to have increased substantially and turned statistically significant in June 2020. The same is observed for intensive caregiving, with a widening gap in mean CES-D scores between non-intensive and intensive caregivers. Caregiving had no effect on psychological well-being for either women or men in 2015, but with mean CES-D scores deteriorating post-onset for all groups, the gap between noncarers and carers was statistically significant in June 2020, albeit only for men.

Results from the linear regression model (Table 5) that includes interaction terms between caregiving and 'postonset' confirm that after the onset of the pandemic psychological well-being deteriorated in the population as a whole (as shown by the significant coefficient for 'post-onset' in the column 'Total'). Furthermore, the interaction term shows that the gap in CES-D scores between non-carers and carers significantly widened by 2.5 units, thus supporting Hypothesis 4.

As for care intensity, the coefficient of the linear regression model shows that intensity is associated with higher CES-D scores and these have deteriorated post-onset of the pandemic. The interaction term in the linear regression model indicates, however, that the widening of the psychological well-being gap between intensive and non-intensive caregivers is not statistically significant, after adjusting for socio-demographic differences. ${ }^{2}$ This suggests that the burden of intensive caregiving relative to less intensive caregiving has not further increased due to the pandemic (no support for Hypothesis 5).

Finally, the interaction terms in the gender-separated linear regression models show that the difference in psychological well-being between male informal carers and male

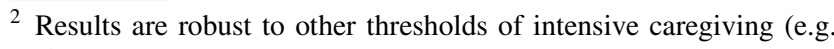
$11 \mathrm{~h}$ or more).
} 
Table 3 Bivariate analysis of profile of noncarers and carers, before and post-onset the pandemic

\begin{tabular}{|c|c|c|c|c|c|c|}
\hline \multirow[t]{3}{*}{ Variable } & \multicolumn{3}{|c|}{ February 2020} & \multicolumn{3}{|l|}{ June 2020} \\
\hline & Non-carers & Carers & $p$-value & Non-carers & Carers & $p$-value \\
\hline & $\%$ (mean) & $\%$ (mean) & & $\%$ (mean) & $\%$ (mean) & \\
\hline \multicolumn{7}{|l|}{ Gender } \\
\hline Women & 46.30 & 56.26 & 0.008 & 46.20 & 56.07 & 0.007 \\
\hline Men & 53.70 & 43.74 & & 53.80 & 43.93 & \\
\hline Age (mean) & $(41.81)$ & $(45.97)$ & $<0.001$ & $(41.75)$ & $(46.0)$ & $<0.001$ \\
\hline $20-29$ & 21.00 & 15.41 & $<0.001$ & 21.15 & 14.91 & $<0.001$ \\
\hline $30-39$ & 23.20 & 15.94 & & 23.09 & 17.23 & \\
\hline $40-49$ & 23.55 & 16.85 & & 23.65 & 16.78 & \\
\hline $50-59$ & 24.27 & 37.14 & & 24.17 & 36.67 & \\
\hline $60-64$ & 7.99 & 14.65 & & 7.93 & 14.42 & \\
\hline \multicolumn{7}{|l|}{ Youngest child } \\
\hline $0-6$ & 17.60 & 12.73 & 0.115 & 17.85 & 11.61 & 0.028 \\
\hline $7-18$ & 24.61 & 22.67 & & 24.64 & 22.66 & \\
\hline $18+/$ no children & 57.79 & 64.60 & & 57.52 & 65.74 & \\
\hline \multicolumn{7}{|l|}{ Education } \\
\hline Primary & 13.69 & 12.61 & 0.922 & 13.60 & 13.21 & 0.983 \\
\hline Secondary & 56.69 & 57.24 & & 56.77 & 56.71 & \\
\hline Tertiary & 29.62 & 30.15 & & 29.62 & 30.09 & \\
\hline \multicolumn{7}{|l|}{ Birth country } \\
\hline Austria & 88.69 & 93.20 & 0.068 & 88.44 & 94.35 & 0.017 \\
\hline Foreign-born & 11.31 & 6.80 & & 11.56 & 5.65 & \\
\hline Household size & $(2.76)$ & $(2.72)$ & 0.610 & $(2.78)$ & $(2.65)$ & 0.161 \\
\hline \multicolumn{7}{|l|}{ Employment } \\
\hline Employed & 76.12 & 70.33 & 0.107 & 73.88 & 64.48 & 0.017 \\
\hline Unemployed & 7.43 & 7.15 & & 10.03 & 13.27 & \\
\hline Inactive & 16.45 & 22.52 & & 16.09 & 22.25 & \\
\hline \multicolumn{7}{|l|}{ Income situation } \\
\hline Comfortably living & 43.17 & 49.89 & 0.125 & 32.74 & 37.14 & 0.005 \\
\hline Managing & 47.90 & 39.41 & & 46.96 & 33.50 & \\
\hline Difficult to manage & 6.63 & 8.79 & & 14.45 & 21.85 & \\
\hline Very difficult to manage & 2.31 & 1.19 & & 5.84 & 7.50 & \\
\hline No. of observations & 1737 & 263 & & 1722 & 278 & \\
\hline
\end{tabular}

Bold indicates significant values at *p $<0.05$; ** $p<0.01$; *** $\mathrm{p}<0.001$

Source Weighted results for AKCOVID non-carers widened by 3.6 units between 2015 and 2020, which pertains to a statistically significant increase in the psychological burden of care for men. Female carers tend to report more depressive symptoms than male carers, yet their burden of care does not appear to have significantly deteriorated any further, as indicated by the non-significant interaction term. Hypothesis 6 is therefore not confirmed, as findings suggest that the psychological burden associated with care worsened post-onset of the pandemic for men yet remained relatively stable for women.

\section{Discussion and conclusions}

Our findings suggest that both the prevalence and intensity of informal care remained stable after the onset of the first wave of the pandemic in Austria (none of Hypotheses 1-3 is supported). This seems to contradict most informal careonly studies that report an increased care intensity, with the exception of a study on the Netherlands (Gräler et al. 2020). However, these prior studies only sampled existing carers-i.e. they did not consider those who stopped providing care-likely under-reporting cessation of caregiving that our pre- and post-onset study design captures. Indeed, among continuous carers in the AKCOVID sample, most did not 
Table 4 Mean CES-D scorescaregiving (disaggregated by gender) and care intensity

\begin{tabular}{|c|c|c|c|c|c|c|c|c|c|}
\hline \multirow[t]{2}{*}{ Variable } & \multicolumn{3}{|l|}{ Total } & \multicolumn{3}{|c|}{ Women } & \multicolumn{3}{|l|}{ Men } \\
\hline & Mean & SD & $p$-value & Mean & SD & $p$-value & Mean & SD & $p$-value \\
\hline \multicolumn{10}{|l|}{ Caregiving } \\
\hline \multicolumn{10}{|l|}{2015} \\
\hline Non-carers & 12.08 & $(9.14)$ & & 12.16 & $(8.89)$ & & 12.01 & $(9.38)$ & \\
\hline Carers & 13.12 & $(9.58)$ & & 13.59 & (10.06) & & 12.39 & $(8.78)$ & \\
\hline \multicolumn{10}{|l|}{ June 2020} \\
\hline Non-carers & 17.44 & $(12.44)$ & & 19.07 & $(12.61)$ & & 16.04 & $(8.78)$ & \\
\hline Carers & 20.74 & $(13.86)$ & $* * *$ & 21.15 & $(14.00)$ & & 20.18 & $(13.71)$ & $*$ \\
\hline Observations & 3153 & & & 1615 & & & 1538 & & \\
\hline \multicolumn{10}{|l|}{ Intensity } \\
\hline \multicolumn{10}{|l|}{2015} \\
\hline Non-intensive carers & 12.36 & $(8.62)$ & & & & & & & \\
\hline Intense carers & 15.99 & $(12.83)$ & & & & & & & \\
\hline \multicolumn{10}{|l|}{ June 2020} \\
\hline Non-intensive carers & 19.20 & $(13.57)$ & & & & & & & \\
\hline Intense carers & 27.23 & (13.90) & $* * *$ & & & & & & \\
\hline Observations & 482 & & & & & & & & \\
\hline
\end{tabular}

${ }^{*} p<0.05 ; * * p<0.01 ; * * * p<0.001$. Intensive caregiving defined as more than $20 \mathrm{~h}$ of care per week. Full linear models include age categories and age categories interacted with post-onset, gender, foreign-born, family composition (children), household size, urban, education (ISCED), income and income interacted with post-onset, employment and employment interacted with post-onset

Table 5 Multivariate OLS estimates (dependent variable: CES-D score)—caregiving (disaggregated by gender) and care intensity

\begin{tabular}{|c|c|c|c|c|c|c|c|c|c|}
\hline \multirow[t]{2}{*}{ Variable } & \multicolumn{3}{|l|}{ Total } & \multicolumn{3}{|c|}{ Women } & \multicolumn{3}{|l|}{ Men } \\
\hline & $b$ & SE & p-value & $b$ & SE & p-value & $b$ & SE & $p$-value \\
\hline \multicolumn{10}{|l|}{ Caregiving status } \\
\hline Caregiving & 0.539 & $(0.665)$ & & .850 & .899 & & .203 & .960 & \\
\hline Post-onset & 5.025 & $(0.780)$ & $* * *$ & 5.146 & 1.137 & $* * *$ & 4.786 & 1.067 & $* * *$ \\
\hline Caregiving $\mathrm{x}$ post-onset & 2.496 & $(1.065)$ & $*$ & 1.634 & 1.412 & & 3.587 & 1.639 & $*$ \\
\hline Observations & 3153 & & & 1615 & & & 1538 & & \\
\hline \multicolumn{10}{|l|}{ Intensity } \\
\hline Intensive caregiving & 4.676 & $(1.778)$ & $* *$ & & & & & & \\
\hline Post-onset & 5.183 & $(2.425)$ & $*$ & & & & & & \\
\hline Intensive caregiving $\mathrm{x}$ post-onset & 3.102 & $(2.625)$ & & & & & & & \\
\hline Observations & 482 & & & & & & & & \\
\hline
\end{tabular}

${ }^{*} p<0.05 ; * * p<0.01 ; * * * p<0.001$. Intensive caregiving defined as more than $20 \mathrm{~h}$ of care per week. Full linear models include age categories and age categories interacted with post-onset, gender, foreign-born, family composition (children), household size, urban, education (ISCED), income and income interacted with post-onset, employment and employment interacted with post-onset

change their care intensity, and those who changed, did so at the margins (i.e. variations below $10 \mathrm{~h}$ ). Both those who stopped and started to care after the onset of the pandemic had similar average care intensities fitting with the profile of the sporadic carer providing help with household tasks (e.g. groceries, collecting medicines). In sum, there are some indications of both a tightening of care networks, but also increasing help with household tasks resulting from higher community solidarity, in line with other studies (Maccora et al. 2020; Rothgang and Wolf-Ostermann 2020; Evandrou et al. 2020). While reverse causality cannot be ruled out, the deteriorating employment and economic situation of informal carers may have partially arisen from increased unpaid informal care causing reductions in hours of paid work (Volkshilfe 2020; Bennett et al. 2020).

A novel aspect of this study is the possibility to compare the effect of caregiving on psychological well-being (i.e. the gap between carers and non-carers) pre- and post-onset 
of the pandemic. Findings confirm that psychological wellbeing has deteriorated more strongly among carers than among non-carers after the onset of the pandemic (Hypothesis 4). As in other studies prior to the pandemic, care intensity was significantly associated with poor psychological outcomes (Buyck et al. 2011; Vlachantoni et al. 2013). We could not however conclude that the gap in average CES-D scores between intensive and non-intensive caregivers widened after the onset of the coronavirus crisis (Hypothesis 5). While we expected the psychological burden of care to have intensified specifically for female carers (Hypothesis 6), this was not confirmed.

The stressors affecting caregivers are likely to be intertwined: emotional, economic and health-related stress (Kent et al. 2020). Caregiving increases worries related to health during the pandemic that in turn may heighten social isolation due to fear of spreading the virus to cared-for relatives (Carers UK 2020; Carers Trust 2020; Kent et al. 2020; Gräler et al. 2020). Informal caregiving may have become more mentally exhausting in that carers had to provide more emotional support for those cared for, as reported in other countries (Gräler et al. 2020). With carers' income situation deteriorating, financial stress may have been another factor increasing perceived burden, while at the same time carers have had to spend more to support those they care for (Bennett et al. 2020). In turn, high-intensity caregivers are less likely to have suffered from changes to employment, as they are much less likely to have been employed from the start (Carmichael et al. 2010).

Three months after the onset of the pandemic both female and male carers had lower psychological well-being compared to non-carers. Among men, but not women, this psychological care burden increased after the onset of the pandemic. That this burden has not further increased for women, seems to be explained by the fact that female noncarers also experienced a marked deterioration of their psychological wellbeing, after the onset of the pandemic. This was much less the case for male non-carers. Overall, the pandemic seems to have had a greater adverse impact on the psychological well-being of women, arguably due to the exacerbation of unequal division of tasks at home (Douglas et al. 2020; Craig and Churchill 2020), rendering the effect of informal caregiving less conspicuous among women.

There are a number of caveats to consider. As we compare two cross-sectional datasets in two time points, we cannot establish causality for these changes. The pre- and post-onset research design for psychological well-being uses data for 2015 as the baseline. One could question whether changes in the association between caregiving and CES-D scores can be attributed solely to the pandemic, in view of possible policy changes in between that could have impacted this association. Since 2015 , there has been a 5.6\% increase in the availability of care services at home and a marked reduction in the costs of residential care with the abolishment of the asset-based means tests in 2018 (BMASGK 2019). The latter resulted in a $15 \%$ increase in care home residents in 2018 alone. Both these changes likely eased the impact of caregiving on psychological well-being up to the onset of the pandemic (i.e. they operate in the opposite direction of the effect we find), thus lending further credence that our findings capture effects of the pandemic. We are unable to discern the living situation of the carer and cared-for person (e.g. cohabitation). Recent data have shown the care burden to be higher during the pandemic only amongst informal carers living with the cared-for person (Lambotte et al. 2020). We were also unable to account for deteriorating health of the cared-for person, for example due to reduced rehabilitative services during the pandemic. Furthermore, as the sample includes those aged 20-64, we cannot generalise our results to informal carers aged 65 or over, who may have experienced heightened worry of contagion, are more likely to care for cohabiting spouses and have themselves poorer health. Finally, while we were able to observe changes in informal caregiving, we could not ascertain whether these changes resulted in unmet needs for the care receiver.

From a policy standpoint, the findings confirm the vulnerability of carers during the pandemic. Our findings call for increased support for women to reduce their overall unpaid work load and targeted support for both male and female carers. Further, the pandemic could provide an opportunity to involve 'new' sporadic carers in support with daily activities also in the future, while avoiding high-intensity care where negative financial and health effects are well-known (Colombo et al. 2011; Carmichael et al. 2010). Carers, in particular intensive carers, are from the start more likely to experience deteriorating employment conditions and to worry about the financial consequences of the crisis. While the Austrian cash-for-care benefit (Pflegegeld) may be used as a 'routed wage', a more sustainable approach would be to invest in and maintain formal care services also in crisis times. At a European level, the voice of informal carers should be made even more visible in the aftermaths of the crisis, in order to ensure maintenance of respite care and community care services in future pandemics.

With a second wave of COVID-19 already underway, this study provides pointers to researchers and policymakers on the impact of the crisis on the well-being of informal carers, who will be crucial in keeping older people safe and protected during the course of this pandemic.

Supplementary Information The online version contains supplementary material available at https://doi.org/10.1007/s10433-021-00611-z. 
Acknowledgements The fieldwork was funded by the Chamber of Labour for Vienna (AK Wien), the European Centre for Social Welfare Policy and Research, and the Institute for Advanced Studies. The authors are thankful for comments from Dr. Kai Leichsenring to earlier drafts and to the two anonymous reviewers and the editors of the special edition for their valuable comments and suggestions.

Funding The fieldwork was funded by the Chamber of Labour for Vienna (AK Wien), the European Centre for Social Welfare Policy and Research, and the Institute for Advanced Studies.

Data availability The anonymised dataset will be available free of charge at the AUSSDA-The Austrian Social Science Data Archive from Spring 2021.

Code availability Coding used for analysis with statistical software Stata 15.0 is available from authors on request.

\section{Declarations}

Conflict of interest The authors confirm that they have no conflict of interests.

\section{References}

Ansolabehere S, Rivers D (2013) Cooperative survey research. Ann Rev Political Sci 16:307-329

Barczyk D, Kredler M (2019) Long-term care across Europe and the United States: the role of informal and formal care. Fisc Stud 40:329-373. https://doi.org/10.1111/1475-5890.12200

Bennett MR, Zhang Y, Yeandle S (2020) Caring and COVID-19: hunger and mental wellbeing. Sustainable care: care matters 2020/01. CIRCLE, University of Sheffield

Bundesministerium für Soziales, Gesundheit, Pflege und Konsumentenschutz (2019) Pflegevorsorgebericht 2018. Vienna: BMASGK

Buyck JF, Bonnaud S, Boumendil A, Andrieu S, Bonenfant S et al (2011) Informal caregiving and self-reported mental and physical health: results from the Gazel Cohort Study. Am J Public Health 101(10):1971-1979. https://doi.org/10.2105/AJPH.2010.300044

Carers Trust (2020) My future, my feelings, my family: how Coronavirus is affecting young carers and young adult carers, and what they want you to do next. Available at: https://carers.org/ what-we-do/our-survey-on-the-impact-of-coronavirus-on-young -carers-and-young-adult-carers

Carers UK (2020) Caring behind closed doors: forgotten families in the coronavirus outbreak. Available at:https://www.carersuk.org/ images/News_and_campaigns/Behind_Closed_Doors_2020/Carin g_behind_closed_doors_April20_pages_web_final.pdf

Carmichael F, Charles S, Hulme C (2010) Who will care? Employment participation and willingness to supply informal care. J Health Econ 29:182-190. https://doi.org/10.1016/j.jhealeco.2009.11.003

Cénat JM, Blais-Rochette C, Kokou-Kpolou CK, Noorishad PG, Mukunzi JN, McIntee SE, Dalexis RD, Goulet MA, Labelle PR (2020) Prevalence of symptoms of depression, anxiety insomnia posttraumatic stress disorder and psychological distress among populations affected by the COVID-19 pandemic: a systematic review and meta-analysis. Psychiatry Res 295:113599. https:// doi.org/10.1016/j.psychres.2020.113599

Colombo F, Llena-Nozal A, Mercier J, Tjadens F (2011) Help wanted? Providing and paying for long-term care. Organisation for Economic Co-operation and Development Publishing
Comas-Herrera A, Zalakaín J, Litwin C, Hsu AT, Lemmon E, Henderson D, Fernández JL (2020) Mortality associated with COVID-19 outbreaks in care homes: early international evidence. LTCcovid.org, International Long-Term Care Policy Network, CPEC-LSE, 26 June 2020

Connor J, Madhavan S, Mokashi M, Amanuel H, Johnson NR, Pace LE, Bartz D (2020) Health risks and outcomes that disproportionately affect women during the Covid-19 pandemic: A review. Soc Sci Med 266:113364. https://doi.org/10.1016/j. socscimed.2020.113364

Craig L, Churchill B (2020) Dual-earner parent couples' work and care during COVID-19. Gend Work Organ. https://doi. org/10.1111/gwao.12497

Douglas M, Katikireddi SV, Taulbut M, McKee M, McCartney G (2020) Mitigating the wider health effects of covid-19 pandemic response. BMJ (Clin Res ed) 369:m1557. https://doi. org/10.1136/bmj.m1557

Ettman CK, Abdalla SM, Cohen GH, Sampson L, Vivier PM, Galea S (2020) Prevalence of depression symptoms in US adults before and during the COVID-19 pandemic. J Am Med Assoc Netw Open 3(9):2019686. https://doi.org/10.1001/jamanetwor kopen.2020.19686

Eurocarers (2020) Covid-19 and care in Norway [Blog post]. Accessed from https://eurocarers.org/covid-19-and-care-in-norway/

Evandrou M, Falkingham J, Qin M, Vlachantoni A (2020) Older and 'staying at home' during lockdown: informal care receipt during the COVID-19 pandemic amongst people aged 70 and over in the UK. https://doi.org/10.31235/osf.io/962dy

Giebel C et al (2020) Impact of COVID-19 related social support service closures on people with dementia and unpaid carers: a qualitative study. Aging Ment Health. https://doi.org/10.1080/13607 863.2020.1822292

Giovannetti ER, Wolff JL, Frick KD, Boult C (2009) Construct validity of the Work Productivity and Activity Impairment questionnaire across informal caregivers of chronically ill older patients. Value Health J Int Soc Pharmacoecon Outcomes Res 12(6):1011-1017. https://doi.org/10.111 $1 / j .1524-4733.2009 .00542 . x$

Gräler L, Bremmerset L, van Excel J, Bakx P, van Bochove M (2020) Informal care in times of public health crisis: objective burden, subjective burden and quality of life of caregivers in the Netherlands during the COVID-19 pandemic. In: Paper presented at the VID conference 'Demographic Aspects of the COVID-19 Pandemic and its Consequences', Vienna, 30.11-1.12.2020. Available at: https://www.oeaw.ac.at/fileadmin/subsites/Institute/VID/PDF/ Conferences/2020/COVID19/Posters/1.5_graeller.pdf

Hale T, Angrist N, Cameron-Blake E, Hallas L, Kira B, Majumdar S, Petherick A, Phillips T, Tatlow H, Webster S (2020). Oxford COVID-19 government response tracker, Blavatnik School of Government

Kalleitner F (2020) Pflege in Österreich in Zeiten von Corona: Veränderungen, Probleme und ihre Auswirkungen [Blog post]. Institut für Wirtschaftssoziologie der Universität Wien. Available at https://viecer.univie.ac.at/corona-blog/corona-blog-beitraege/ blog65/

Kent EE, Ornstein KA, Dionne-Odom JN (2020) The family caregiving crisis meets an actual pandemic. J Pain Symptom Manag 60(1):e66-e69. https://doi.org/10.1016/j.jpainsymma n.2020.04.006

Lambotte D, de Koker B, de Bruyne N, de Witte N (2020) De beleving van mantelzorgers in tijden van COVID-19. HoGent. Available at: https://steunpuntmantelzorg.be/wp-content/uploads/2020/11/ Onderzoeksresultaten_de-beleving-van-mantelzorgers-in-tijde n-van-COVID-19.pdf 
Lorenz-Dant K (2020) Germany and the COVID-19 long-term care situation. LTCcovid, International Long Term Care Policy Network, CPEC-LSE

Maccora J, Ee N, Hosking D, McCallum J (2020) Who Cares? Older Australians do. National Seniors, Canberra

Marchand A, Bilodeau J, Demers A, Beauregard N, Durand P, Haines VY (2016) Gendered depression: vulnerability or exposure to work and family stressors? Soc Sci Med 166:160-168. https:// doi.org/10.1016/j.socscimed.2016.08.021

McGinty EE, Presskreischer R, Han H, Barry CL (2020) Psychological distress and loneliness reported by US adults in 2018 and April 2020. J Am Med Assoc 324(1):93-94. https://doi.org/10.1001/ jama.2020.9740

Nagl-Cupal M, Kolland F, Zartler U, Mayer H, Bittner M, Koller M, Parisot V, Stöhr D (2018) Angehörigenpflege in Österreich. Einsicht in die Situation pflegender Angehöriger und in die Entwicklung informeller Pflegenetzwerke. Wien, Universität Wien

Pasek J (2016) When will nonprobability surveys mirror probability surveys? Considering types of inference and weighting strategies as criteria for correspondence. Int J Public Opin Res 28:269-291

Revilla M, Saris W, Loewe G, Ochoa C (2015) Can a non-probabilistic online panel achive question quality similar to that of the European Social Survey? Int J Market Res 57(3):395-412. https://doi. org/10.2501/IJMR-2015-034

Rothgang H, Wolf-Ostermann K (2020) Zur Situation der häuslichen Pflege in Deutschland während der Corona-Pandemie: Ergebnisse einer Online-Befragung von informellen Pflegepersonen im erwerbsfähigen Alter. SOCIUM, Bremen, Germany

Schmidt AE, Leichsenring K, Staflinger H, Litwin C, Bauer A (2020) The impact of COVID19 on users and providers of long-term care services in Austria, Country report in LTCcovid.org, International Long-Term Care Policy Network, CPEC-LSE, 16th April 2020
Statistik Austria (2020) Austrian labour market during the corona crisis: $3 \%$ fewer employees in the second quarter 2020, working hours gradually normalising in June [Press release]. Accessed from http://www.statistik.at/web_en/press/124280.html

Taylor DH, Kuchibhatla M, Ostbye T, Plassman BL, Clipp EC (2008) The effect of spousal caregiving and bereavement on depressive symptoms. Aging Ment Health 12(1):100-107

Verbakel E, Tamlagsrønning S, Winstone L, Fjær EL, Eikemo TA. (2017) Informal care in Europe: findings from the European Social Survey (2014) special module on the social determinants of health. Europ J Public Health. 27(1):90-95. https://doi. org/10.1093/eurpub/ckw229.

Vlachantoni A, Evandrou M, Falkingham J, Robards J (2013) Informal care, health and mortality. Maturitas 74:114-118. https://doi. org/10.1016/j.maturitas.2012.10.013

Volkshilfe (2020) Pflege in Österreich: Mehr, besser, bunter. Accessed from: https://www.volkshilfe.at/fileadmin/user_upload/Media _Library/Bilder/Was_wir_tun/2020_Sozialbarometer_Pflege/ Presseunterlage_Sozialbarometer_Pflege.pdf

World Health Organization (2020) Preventing and managing COVID19 across long-term care services: policy brief. Geneva: World Health Organization;. (WHO/2019-nCoV/Policy_Brief/Longterm_Care/2020.1). Licence: CC BY-NC-SA 3.0 IGO

Publisher's Note Springer Nature remains neutral with regard to jurisdictional claims in published maps and institutional affiliations. 